International Journal of English Literature and Social Sciences
Vol-7, Issue-1; Jan-Feb, 2022
Journal Home Page Available: https://ijels.com/
Journal DOI: $10.22161 /$ ijels

Peer-Reviewed Journal

\title{
Redrawing the Boundaries and Creating New Homes: A Study of the Chitra Banerjee Divakaruni's novel Sister of
} My Heart

\author{
Nisha Rakwal
}

TGT (English) JNV Ramban, Jammu and Kashmir, India

Received: 11 Dec 2021; Received in revised form: 12 Jan 2022; Accepted: 18 Jan 2022; Available online: 25 Jan 2022 C 2022 The Author(s). Published by Infogain Publication. This is an open access article under the CC BY license (https://creativecommons.org/licenses/by/4.0/).

\begin{abstract}
Sister of My Heart (1999) is a novel written in a realistic mode embellished by the myths, folktales and fairy tales about India and Hindu religion. The novel traces the conflict and angst the characters in the novel experience as they make fine negotiations between the two worlds, the traditional and the modern and how these characters change in this process balancing the old treasured beliefs and surprising new desires. This Research paper aims at studying the varied aspects of identity crisis, hegemony, patriarchy etc in the Eastern as well as Western context.
\end{abstract}

Keywords-Postcolonial, hegemony, Patriarchy, transcultural, mythological metaphors.

\section{INTRODUCTION}

The protagonists in the novel Sister of My Heart are the two cousins, Anju and Sudha born on the same day opening their eyes to the ill-fated death of their fathers, also brothers of the same family, Gopal and Bijoy respectively, on a ruby exploration journey. The story revolves around the two women caught between hardcore family traditions and modern thoughts of the 1980s.

The novel explores the tension between the desires of mothers who embrace traditional Indian Culture and the two young girls who espouse the new western culture. The two girls Anju and Sudha are positioned against their mother figures that represent the diktat of normative patriarchal concepts. During postcolonial era, women experience double subjection due to race and gender. Their lives are affected by both patriarchal system as well as western hegemonic discourses. At this point of time, men who have been feminist under the empire have acquired assertive roles and aggressive masculinity which left women with no option except to be regarded as savior of national values and carrier of culture. They are restricted to being only mothers and have to follow the traditions of the family and can-not even question it.
In Sister of My Heart, Divakaruni writing from post-colonial position challenges the imperial and patriarchal discourses simultaneously. Through Sudha who is introduced as being passive, rooted in tradition and unquestioningly accepting the stringent codes of conduct set by the family, Divakaruni Challenges male superiority and uses Anju, the more rebellious of the two girls, to demolish the western myth of superiority and validity. Deeply attached to each other the two women get separated only by their marriages; Anju migrates to America with her husband Sunil and Sudha stays in India with Ramesh. Thus, the novel becomes the combination of two stories that take place in two different countries and cultures.

The novel's forty-two chapters are set as a sort of extended dialogue that is multi-layered and overlayered. The chapters themselves are, alternately titled, Anju and Sudha, and contain within their folds, techniques that are epistolary and explanative, topography that is transcultural, tone that is adjectival and highly lyrical, and style that is italicized and romantic. The novel is divided into two halves, namely The Princess in the Palace of Snakes and The Queen of Swords named after the stories the girls tell each other. Often the events of the novel 
parallel the happenings in these stories. Also mixed in with these stories, are Bengali Myths and stories of the Gods in the Hindu tradition.

Being, herself an Indian exile in USA, Divakaruni does not escape the retention of her childhood memories which are nourished by the folk tales, myths, legends and epics of Ramayana and Mahabharata told by her grandfather to her. Though Sister of My heart depend less on magic realism, Divakaruni has employed the element of myth and fairy tale in it. In fact, it is not a rejection of myths but an adaptation of them to suit the needs of modern women that is desirable.

In Divakaruni's work, the context, figures and situations are mythological but the reactions and responses of her protagonists are akin to those of contemporary women. The first book in the novel is titled as The Princess in the Palace of Snakes. In this part both the protagonists attempt to conform to the traditional feminine roles allocated by the male hegemonic society. This is symbolized by the traditional fairy tale of a princess "who lived in an underwater palace filled with snakes. The snakes were beautiful- green and yellow and gold and gentle. They fed her and played with her and sang a song to her to sleep" (SMH 101).

But Divakaruni reinterprets the myth and shows how princess instead of waiting for her prince charming to come and rescue her, generates courage and flees from the dungeon of the traditional world to attain freedom and self assertion. The second book is titled as The Queen of the Swords and it is not a traditional fairy tale. When Anju is upset over her miscarriage, Sudha tells her the tale of 'Queen of Swords' and how she rescues her child and herself from the enemies and relates it to what happened to their three mothers and to her. Divakaruni makes use of mythological metaphors to accentuate the liveliness of experiences her characters under go.

The first part of the novel, The Princess in the Palace of Snakes, follows the two cousins from birth until their wedding day. Born few hours apart from each other on the same day in a big old Calcutta house, Sudha and Anju are the distant cousins and are brought up together by their widowed mothers and aunt, Pishi. More than sisters do, they share clothes, worries, and dreams. They have been bonded in ways even their mothers cannot comprehend. It is apparent through Anju's reminiscences that Anju and Sudha are devoted to each other:

All through childhood we bathed together and ate together, often from the same plate, feeding each other our favourite items, the crunchy brown triangles of paronthas, fried egg plant, spongy-sweet rasogollah balls. Our favourite game was acting out the fairy tales Pishi told us, where Sudha was always the princess and I the prince who rescued her ... And when we had nightmares, instead of going to our mothers for comfort, we squeezed into one bed and held each other. (SMH 25)

The novel unfolds in the alternating voices of the beautiful story teller Sudha and the outspoken Anju, "the girl-babies who are so much bad luck that they cause their fathers to die even before they are born" (SMH 6). The usually quiet Sudha observes that, even at birth, Anju had called her out into the world. Their determination sustains them both through the difficulties and deceptions they encounter as adults. Although the two girls are inseparable, they are different in their personalities and ambitions. Anju is somewhat physically unattractive, practical, challenges tradition, enjoys reading, and hopes to travel and a rebel who dreams of higher education. On the other hand, Sudha is beautiful, romantic, and conventional, likes clothes and concocts stories based on Hindu fables and legends. Along with the difference in personalities, the girls also belong to different socio-economic backgrounds. Anju is a proud descendent of the wealthy Chatterjee family and thus, has more social and economic advantages than Sudha that permit her to transcend the restrictive demands of traditional Hindu Indian female gender notions, which might eventually prevent her from fulfilling the roles of wife and mother. Anju gets the privilege of concentrating on her studies as well as her career, despite the calamities that she has faced in her life:

On the other hand, Sudha and her mother are socially and economically disadvantaged and come from the branch of the family tree that is shadowy and dark. They have to depend on the good graces of Gauri Ma and hence, Sudha is more likely to fall under the burden of the traditional Hindu-Indian gender norms. Being a beautiful girl the only way to prevent herself from falling prey to traditional Hindu-Indian gender norms is by securing a good husband. Sudha's dream for the future is to have a happy and intact family, to become a wife and mother, steeped in the Indian culture. She says:

Perhaps he writes beauty, for though I myself do not think so, people say I am beautiful even more than my mother was in the first years of her marriage. Perhaps he writes goodness, for though I am not as obedient as my mother would like, I try hard to be good. (SMH 21-22)

Bound by tradition and stifled by the fact that they are women, the three mothers strive hard to run the family. Gouri Ma is Anju's mother and head of the Chatterjee household and has the responsibility to run the family. Gouri Ma risks her health by managing the family bookstore. Nalini, Sudha's mother, wants to lead a luxurious life. In order to fulfil her wishes her husband 
persuades Anju's father to go in search of treasures. In that adventure the mysterious death occurs. The two women are burdened by the violent and mysterious deaths of their husbands. Pishi, Anju's and Sudha's aunt tells the children stories and plays a pivotal role in upholding the prestige of the Chatterjee house.

But Anju resists the mothers and wishes to step out of the Dark Ages into the modern world of 1980s: "Or is it because I am a daughter that my happiness doesn't matter?" Anju's voice wobbles and she is about to cry. This is her cry against all things traditional. She is determined not to follow the footsteps of the women of the Chatterjee household. She yearns to be modern in her thinking and attitude. She confronts her mother saying, "I bet if I were a boy you wouldn't be saying no to me all the time like this" (SMH 53). Through Anju, Divakaruni explores the psyche of the middle class educated Indian women, focusing primarily on her dilemma at being caught between modernity which implies freedom, individuality and self-expression and the patriarchal and traditional values that continue to permeate contemporary Indian society.

Anju and Sudha find solace in the company of each other and become each other's alter-ego. However, adult life has preferences and designs that rarely approve sisterly bonds. For Indian women, marriage is the norm even for those who aspire to attend college as Anju does, or for those who fall in love at first sight, as Sudha. Sudha is madly in love with Ashok but when it actually comes to standing against her mother's wishes, she has an 'unfocussed look in her eyes'. Sudha contrasts her life to the fairy tale dreams, where she is rescued from monsters by the prince "when in some place deep inside her impervious to logic, she turned Ashok into the prince who has to save her from the clutches of the wicked king" (SMH 100). She wants to spend her life with Ashok but being a fatherless child she cannot afford to take a radical step of getting married against her mother's desires. She is bound by her own psyche and the traditional Sati Savitri Syndrome which tells her that it is wrong to go against her mother's wishes and make her unhappy.

Nalini Ma, Sudha's mother, finds a suitable match for Sudha within their own caste and a respectable one. Sudha and Ashok start making plans of getting married secretly. However, when Sudha discovers a dark secret about her father, her whole life changes. It tests her relationship with Anju: "Something has changed between us, some innocence faded like earliest light" (SMH 39) and she vows to "spend the rest of my life making up to her for the way in which my father had deceived hers" (SMH 55). It is from Pishi that Sudha comes to know that her father was an imposter and had caused the death of Anju's father.
Assuming the moral responsibility for her father's act, she develops maturity and independence that emboldens her to take major decisions in life without even consulting Anju with whom she once shared a symbiotic relationship.

Out of a sense of familial obligation, Sudha agrees to an arranged marriage and sacrifices her love for Ashok, since Anju's marriage hinges on a spotless family reputation. Sunil's father would never let him marry a girl whose cousin had eloped with a man she met in a movie house and that too of a lower caste. One of the differences between the eastern and western culture is their mode of social stratification:

Eventually the two girls get married on the same day, Anju to Sunil, a computer scientist working in America and Sudha to Ramesh, an employee in Indian Railways. The string of the bond of both the sisters is somewhat stretched when Anju perceives her husband Sunil's infatuation for Sudha's beauty:

The wedding dinner is over. We use to sit and Ramesh and Sudha walk ahead, his arm under her reluctant elbow. She pulls out a handkerchief to wipe her face. She replaces it- but no, it falls behind the table. No one notices Sunil bending to pick it up, to slip into his pocket where he fists his hand around it. No one except me. (SMH 322)

When Anju visits Sudha's house before leaving for America, she comprehends that "marriage has complicated their lives, divided their loyalties and has set them on their different wifely orbits" (SMH 176). The first part of the novel ends with Anju moving to America and Sudha moving to her husband and in-law's home.

In the second part of the novel, The Queen of Swords, amidst the different settings and ideologies, the writer brings home the similarities of situation between life in traditional India and modernized America through psychological and physiological changes accompanied with the experience of pregnancy of the two cousins. Being geographically apart, Anju and Sudha correspond only through letters. Sudha discovers letters to be much more pleasant and comforting. She is of the opinion that in the letters the world can be reduced "to an inch-wide window and can-be idealized like a touched up photograph" (SMH 180). Sudha realizes her inability to adjust herself to a passionless marriage. She reflects thus:

My days have such sameness to them, a hypnotic placidity, like a pool into which nothing ever falls, leaf or stone or human life. I float on this pool. I know I am needed, I know I am liked. And so I am not unhappy. (SMH 179)

Here begins a tale that is wrought with the dilemma of immigration and dislocation of enforced 
silence and concocted invisibility, the dialectic of what the author calls, "opposing desires" (SMH 119). Anju and Sudha get married and attempt to deal, respectively with the fluctuating undulations in the life of an immigrant woman in the US, and the placid life of conformity led by a married woman, back in India. "The house of marriage", turns out to be for both the women, like "many locked rooms" (SMH 166), as Sudha begins to wilt under the duress of 'ownership' that her husband claims on her, while Anju strives to ward off everyone who appears like 'an intruder' on her freedom, including her tyrannical father-in-law.

Ramesh's mother, Mrs. Sanyal, spreads her dominance through the whole household. A few days after the wedding, Sudha's stern mother-in-law, calls Sudha to her room and hands over a ring of keys to Sudha with the instruction, "Natun Bau ... this is your home now. You must learn to take charge of it" (SMH 168). It is difficult for Mrs. Sanyal to give up responsibilities. But she is determined to do so because of her loyalty to the Sanyal family. "That was why she gave me those keys, symbol of shared power ... not so much because she liked me ... she hardly knew me, after all ... but because I belonged to the family now" (SMH 169). Paramjit Kaur also avers in the following lines:

Tradition is deep-rooted in India and in the traditional system Indian society is organized around gender division giving more space to male for dominance. Right from the marriage, the bride's incorporation into the family begins. She is guided and trained into the life style of her husband's family. But despite her all efforts to devote herself sincerely to the well-being of the family she is considered as an outsider. (26)

Although circumstances differ in America, the predicament remains the same for Anju as for Sudha. Anju discovers that marriage and her adopted land America belie her expectations. Her daily routine in America is to drive Sunil to the station; then attend her classes; write some assignments of the library; visit the grocery and the drycleaners. Of the many realizations, the foremost one that she has discovered is that she hates cooking. In the evening again she has to prepare dinner and drive Sunil home. This is entirely different from her dreams. She had visualized America where she would be free to do whatever she desired. Anju does not wish to lead a mechanical life, which according to her is Indian. She dreams of a healthy, happy relationship with Sunil according to a western model of equality and respect, but the western image has actually trapped her into a conventional bond with all the associated problems.
In Anju, Divakaruni presents the cultural bias of the colonized hybrid. She is an ardent admirer of western literature and constantly interrogates the validity of the native culture. Being an ardent admirer of Virginia Woolf's A Room of One's Own, she records her feelings for the book that serves as an interpretive lens to her mental attitude which still carries the colonial baggage:

Woolf has been a favourite of mine since the time I stumbled upon one of her books at the store. It was a beautiful, old, leather bound volume, printed in England, with an intriguing title, A Room of One's Own. When I put my nose to the thick pages, they smelled unlike Indian books with their rice-glue binding. I thought of it as the smell of distance, of new thinking. That smell stayed with me a long time. It stood for something I wanted but didn't know a name for. (SMH 134)

True to the culture of America Sunil has feigned nature. Anju is not competent enough to fully understand the nature of Sunil. Sunil inquires about the welfare of the mothers; but he does not pronounce a word about Sudha, does not even pick up the mail, if there is one from Sudha in the stack. Anju could not neglect the look on Sunil's face as he gazes after Sudha as he picks up the handkerchief that has fallen from her waistband on the eve of their wedding.

Once when Anju is sick, he sits up all night massaging her feet and holding a basin for her to throw up in. Yet another time when Anju runs out of writing paper and searches in his desk drawer for some paper, he shouts at her for not respecting his privacy. Sunil consistently encourages Anju to feel comfortable in America. He teaches her to drive and introduces her to his colleagues at work. He accompanies her to the malls, plays, dance clubs and ocean.

Sunil is typically American in his attitude. Earlier in the novel, Sunil arrives directly at Anju's book store to see her (for the purpose of proposed marriage) in an informal surrounding which is due to the American influence. At Chatterjee house too, his taking cups of tea around to everyone, shaking hands with Sudha and a clear refusal to his father for dowry are something that appear wholly non-Indian about him. These reflections in the story indicate that "the change of geographical boundaries can intensely affect the mind set up which is rooted deeply in the traditions of native country" (Agnihotri 4). When Sunil has an argument with his father, his father shouts at him saying, "I wonder how impressed she be if she knew about your American exploits, all that drinking and whoring" (SMH 197).

The deceptive personality of Sunil comes as a shock to Anju. She has been brought up in a traditional 
Indian home and deceptiveness is alien to the Indian way of life. Sunil's deception is the beginning of Anju's disillusionment with the western sophistication. She soon realizes, "It's not what I imagined my American life would be like" (SMH 186). Anu celly Narula comment on this position of Anju:

Anju's dream of uncompromised freedom in the land that they call America begins to be invaded by the rude realization of being an 'outsider' both at home and in society. As she attempts to come to terms with a mechanized, colourless existence, her sensibility revolts against being branded an 'illegitimate alien', even by a speeding stranger driving on the road ... the dichotomy inherent to the situation of the immigrant populace, as they straddle between the conflicting choices of conformity and rebellion, enhancement and degradation, loyalty and injured merit. (58)

Anju's decision to join college and take on a job bespeaks of her need for empowerment even in the face of her husband's scathing indifference. Anju's situation reflects the dilemma of "duplicity", inherent to self defeating choices that are sometimes faced by migrant women, who strive for a sense of wholeness and selfesteem amidst fragmentation and estrangement, through education and self-reliance.

Anju cannot cope with the challenges of the new world and starts falling into deep despair and disillusionment. It is only when Sudha tells a story based on Indian mythology to Anju over the phone her drooping spirit is revitalized. Right from her childhood, Sudha is gifted with the power to invent and interpret stories based on aunt Pishi's mythological tales. Pishi used to tell the story of a princess and also the story of a brave warrior queen who defends herself and her baby against an army who are trying to harm her. But Sudha reinterprets the myths and and princess instead of waiting for her prince charming to rescue her, generates courage and flees from the dungeon of traditional world to attain freedom and selfassertion by seeking an asylum with women.

Divakaruni has shown through her fiction that our tradition and myths have helped Indian immigrants to establish their roots in an alien land.

The thematic pattern strands together the fate of Anju and Sudha, exposing them both to the daunting determinism of familial expectations, as custodians of what constitutes an authentic notion of Indianness. According to Emily Skop:

As cultural custodians, Indian women become the primary transmitters of religious and cultural traditions within the household and in local associations. Thus, their socio-economic achievements are less likely to be celebrated than perhaps their success as mothers and community preservationists. (277)

Precisely, the same kind of socio-moral determinism now coils around Sudha, as she resents being branded worthless, since she can-not conceive a child. Life brings Sudha and Anju to the same stage of life when they both become pregnant. Sudha feels immensely happy.

I am so delighted I could dance- remember the way we used to clasp hands up on the old terrace, and whirl and whirl until everything become a blur of light? I am delighted ... for us both ... I am going to be a mother too! Oh, Anju how I wish we could be together now! (SMH 213)

The news of Sudha's pregnancy gladdens the household of Mrs. Sanyal. After the pregnancy, Sudha's mother-in-law relieves her from house hold work. Now that Sudha is pregnant, she enjoys certain liberties. The entire family is jubilant over the news. But things take on a different frame, when the test establishes that Sudha will deliver a baby girl. Mrs. Sanyal declares that, the eldest child of the Sanyal family has to be male and hence Sudha has to undergo an abortion. Sudha is shocked but her husband Ramesh fails to come to her rescue. He is a decent man and a loving husband but in the presence of his mother "he is like a leaf in the gale" (SMH 197).

The attitude of Mrs. Sanyal and Ramesh's demeanor impels Sudha to leave her in-laws' home and proceed to her mother's home at Calcutta. Sudha is not willing to abort the foetus just because it is a female. Her mother Nalini also counsels her to yield to Mrs. Sanyal. As a Chatterjee woman she has no choices. The family reputation is more important. Sudha is an obedient daughter, a dutiful wife and a well-mannered daughter-inlaw. But when the relationship between her and her daughter is challenged, she progresses from subordination to an emancipated mother. This emancipation is a deliverance from her Indian roots. As an Indian, she honors and admires all that is Indian, she feels subordinated in order to entertain and gratify the people around her and whom she encounters but becomes empowered when she has to confront and tackle the problem of her pregnancy and abortion. Sudha finds it hard to put a lid over:

The dormant and conflictual sense of an aching emptiness and a chiaroscuro of anger, sorrow and anxiety aimed at the societal norm that perpetuates female foeticide, and which propagates a belief that a woman achieves her purpose only with bringing a male progeny into the world. (Narula 59)

Moreover, through the characters of Sunil and Ramesh, Divakaruni portrays the difference between 
eastern culture and western thought. Eastern society is so family oriented that you give up your individual desires for the good of the family. In the western society people are individualistic. They never do any compromises with their desires and if the family doesn't agree with them, they forget the family. True to the culture of America, Sunil remains detached from his parents, after a small misunderstanding with his father. He even settles the amount spent by his father for his education. On the contrary, Ramesh remains a good son to his mother. He is not bothered about Sudha when his mother compels Sudha to abort the girl child. He is attached to his family, and feels bonded to his mother and brothers than his wife.

Further, Nalini Ma, Sudha's mother, primarily comes across as a woman doubly handicapped in attitude, first by a patriarchal tradition, and second by the modern need for reinforcing identities. She does not hesitate to sacrifice her own daughter's happiness or even her granddaughter life, when it comes to saving face in her honor-conscious prestige and scandal obsessed society. The upholder of the family tradition, Pishi and Gouri Ma, come to the rescue of Sudha. Gouri Ma adjudges Sudha to be old enough to make her own decisions and Pishi consoles her that Sanyals have not realized the worth of Sudha. Sudha has a whole life in front of her and the life will be a success and that will leave the Sanyals gaping.

When Pishi pronounces it with such zest that Sudha's future offers scope for a happy life ahead, Sudha desires the women of the Chatterjee home to bless her to be like the Rani of Jhansi, the 'Queen of Swords'. She wants them to bless her thus:

Bless me that I have the courage to go into battle when necessary no matter how black the situation. Bless me that I may be able to fight for myself and my child, no matter where I am. (SMH 49)

Sudha's decision to get separated from Ramesh is not an Indian woman's way of life. Her behavior shows that a marriage bond will have meaning only if there is mutual love and respect. Otherwise it would be a mechanical existence. Sudha has successfully wriggled herself out of the stifling influences of tradition and has started to think about living her life for herself and her daughter. By identifying with this legendary Indian woman, Rani of Jhansi, Sudha is able to be brave, travelling alone in public in order to save her daughter. "I swat his hand away furiously and, kick at the ankles of a fat man blocking my path ... May be this is how the Rani of Jhansi felt the first time she went to war (SMH 243)".

Sudha's courage, her love for her daughter, and her success in reaching her family's house safely reaffirms her choice to leave her husband. When Anju comes to know about Sudha's prospects, she expresses her wish in a letter that Sudha and her daughter should visit America. In her view, America has its own problems like the clash of values and different life style, but at least it will give Sudha the advantage of anonymity. In such a situation, Sudha can carve out a new life, earn her own living and provide her daughter everything that is necessary. Sudha, eventually, decides to leave for America on Anju's invitation.

Although Sudha's girlhood love proposes to her, he doesn't really want Sudha's child, so Sudha refuses him and eventually, decides to go to Anju in America. Anju, too, has marital difficulties. She loves Sunil, but imagines he is having affairs and is disturbed to find that he expects her to be grateful to him for marrying her.

Moreover, in order to meet Sudha in America, Anju has paid a heavy price. Anju loses her son who was named Prem before birth in a miscarriage. Anju toils extra hours to save money for Sudha's ticket. Sunil is not pleased about Anju's exertion. Inspite of her pregnancy, Anju strains physically and that results in an abortion. Anju forfeits her son Prem for the sake of Sudha. In the hospital, Anju exclaims, "My baby, I killed him" (SMH 282). When Sudha speaks to Anju on the phone after Anju's miscarriage, Sudha reveals the story of Lord Krishna who helped his sister Draupadi in times of need and compares the lost child of Anju to be Lord Krishna in the symbol of a star in the sky thus leading Dayita to a bright future. This helps in reaffirming Anju's power and encouraging her to heal herself.

Despite all these bewilderments Anju is enthusiasitic to welcome her sister of the heart, Sudha to the land of her choice.

This summarized progression from India to America might easily be understood as a stereotypical reification of cultural Boundaries where India manifests all the traditional Indian patriarchal restrictions under which Anju and Sudha suffer and where America promises possibilities not only for Anju, who can work, take classes, and wear jeans, but especially for the divorced Sudha who would, along with her child, face discrimination in India. (Subhasini 56)

Sudha is prepared to leave for America with Dayita. Nothing could dissuade Sudha or coerces her to feel apologetic or induce her to think over again about her resolution. Thus Sudha finds herself on her way to selfempowerment. She swears thus: "I will prove myself. I will be in charge of my fate. I will pattern a new life for myself I swat the superstitious uncase that buzzes in my car like gnats" (SMH 273). 
Once again, it's at a climatic juncture that Anju imparts to Sudha, the strength of a reckless decision, which encourages her to take on a "hard journey" (SMH 241), away from her in-law's house armed with a level of audacity to expunge the injustice of a marital tie that inhibits her individuality. Sudha personifies much like Anju, the portrait of women who want to forge a whole new future that is free of the compelling need to surrender to the creed of women's denigration. Sudha's unfaltering resolve, in this instance, matches Anju's ordinate will power, enabling her to nurture both her new-found independence and her baby girl from the wake of a divorce from her husband, and a denial for her ex-lover's attempt to come back into her life. Sudha's deft artistry in stitching a quilt with multiple colors, symbolizes her desire to weave the pattern of a new lease of life, which beckons her through Anju's offer to help her migrate to the US.

At the time of their journey, Sudha discloses the story of the 'Queen of Swords' in Dayita's ears. Sudha cannot ensure Dayita of a happy life ever after, because Sudha is unaware of the kind of life in America.

Despite the clouded fear of being an "alien" who can be a burden for her host family. Sudha feels invigorated with the prospect of anonymity and solidarity that life in America would bring to her. She affirms:

I am going for Anju, yes, and for Dayita, but most of all I am going or me. I am going with the knowledge that this will not be a fairy- tale journey, my winged steed leaping over all obstacles with unfailing ease, but I am going anyway. Do I want to return? And if I do return, will I be happy tying myself to a man's whim again, even if he is a good man? (SMH 316)

Through the various interactions of Sudha and Anju with their lovers, husbands and in-laws, Divakaruni often brings out the negative aspects of the traditional Indian society. As Anju grudgingly points out, this society wants its women to be nothing more than "good breeding stock" (SMH 98), while men are spineless jelly fish even as their yet to be born female infants face death at the hands of a cruel, uncompromising society that prefers boys. Divakaruni's writings do not stop at exposing the traditional Indian society for denying their women freedom, humanity, and the right to live.

However, Divakaruni has delineated both the western and eastern culture in the novel with its own evils and shortcomings. Freedom and riches in the west are often bought, particularly by the immigrant at the expense of the love and support provided by the extended family or the community. Hence the same Anju, who use to complain about the noise and lack of privacy in her mother's home back in India now ardently yearns for the din and hustle in her desolate apartment in America. Indeed America provides "the advantage of anonymity". But it also adds the burden of responsibility and loneliness. No doubt America adds to the self confidence of the Indian male, endowing him with a certain light- heartedness and ease that allow him to trust his partner's vivacity and enterprise which comes in place of domesticity and docility. But America may also turn him into a reckless philanderer, as seen in the character of Sunil, Anju's Americanized husband.

Finally, Sudha arrives in America with her daughter, Dayita. Coming together, however, does not resolve the individual problems of Anju and Sudha. Sudha is aware of the fact that her presence in Anju's marriage will cause problems and unhappiness. Anju is clever, but she is less imaginative and is ready to sacrifice her relationship with Sunil to help Sudha find her own space in America. Thus, Anju and Sudha are reunited, sharing the joy of parenting Dayita who binds them together as they integrate their time tested bond with the renewed hope for a fulfilled future. The novel closes with Anju's thought:

We have formed a tableau, two women, their arms entwined, like lotus stalks smiling down at the baby between them. Two women who have travelled the vale of sorrow and the baby who will save them, who has saved them already. Madonna's with child ... for now the three of us stand unhurried, feeling the way we fit, skin on skin, into each other's lives. A rain-dampened sun struggles from the clouds to frame us in its hesitant holy light? (SMH 349)

Thus, the novel ends not with the celebration of assimilation but with the creation of a new identity and a new home. Sudha's and Anju's coming together, helps in recharging their energy to face life anew. Commenting on the ending of the novel, C.N. Eswari writes:

By synthesizing these two contradictory yet complementary characters, Divakaruni succeeds in presenting the new identity of the immigrant who validates the cultural part to reconstruct a meaning full present in the new world? (217)

Thus, Chitra Banerjee Divakaruni's novel Sister of My Heart, celebrates the tenuous bonds between women, tried and tested against the citadel of convention, the strife of being torn between two worlds, the traditional India and modernized west.

The relationship they enjoy becomes symptomatic of a hybridized sensibility as it bridges the gap between home and exile, subjectively and agency, domination and subjugation as well as exposes the slippages inherent to our construct of ethnicity, sexuality, and identity against the broader frame work of a 
transcultural experience that gravitates between India and America. (Narula 52)

In the fiction of Divakaruni, connections between women consolidate the platform from which women struggle to find their identity. In Sister of $M y$ Heart, the relationship between Sudha and Anju builds up the space of interventions that enable both women to extricate themselves from meaningless relationships and rewrite their strategies of survivals. Hence Sister of $M y$ Heart is the microcosmic representation of the lives lived by women who are caught in the cross-roads of a cultural shift as they try to balance eastern culture with western thoughts.

\section{REFERENCES}

[1] Agnihotri, Neeraj. "Diasporic Consciousness in Chitra Banerjee Divakaruni's Sister of My Heart." Galaxy 3.1 (2014): 1-6. Web. 18 Feb. 2014. <http: // www.galaxyimrj.com/>

[2] Aldama, Frederick Luis. "Unbraiding Tradition: An Interview with Chitra Divakaruni." JSAL 35.1/2 (2000): 112. JSTOR. Web. 19 Sep. 2013. <http://www.jstor.org/stable/40873759/>

[3] Alexander, Meena. The Shock of Arrival: Reflections on Postcolonial Experience. Boston: South P, 1996. Print.

[4] Banerjee, Debjani. “'Home and US': Redefining Identity in the South Asian Diaspora through the Writings of Chitra Banerjee Divakawruni and Meena Alexander." Diasporic Imagination: Asian American Writing. Ed. Somdatta Mandal. Vol. 3. New Delhi: Prestige, 2002. 10-30. Print.

[5] Deshpande, Shashi. "Telling Our Own Stories." Writing From the Margin and Other Essays. India: Penguin, 2003. Print.

[6] Kaur, Paramjit. "Tradition v/s Modernity in Manju Kapur's Novel - Difficult daughters.” IJAR 3.6 (2013): 42-43. Print.

[7] Narula, Anu Celly. "Forms of Hybrid Consciousness and Female Bonding in Chitra Banerjee Divakaruni's Sister of My Heart." Postmodern Indian English Fiction: Some Perspectives. Ed. Abha Shukla Kaushik. Jaipur: Aadi, 2012. 52-61. Print. 